motion hitherto unsuspected, and he has obtained a value for the motion which he believes to be more correct than could be determined by ordinary micrometric measures. In this case a period of fourteen years separated the times of taking the photographs (Comples rendus, No. 19, 1906).

Measures of Double and Multiple Stars.-The measures of 1066 double and multiple stars are published in vol. ii., part iii. (astronomical series), of the Publications of the University of Pennsylvania by Prof. Doolittle.

The measures were made with a wire micrometer attached to the 18 -inch refractor of the Flower Observatory, and include, among others, 733 Burnham stars, I09 $\mathrm{O} \Sigma$, and $\mathrm{IO2} \Sigma$ stars. Four hundred and ninety-two stars from Prof. Hough's catalogue have also been remeasured but are not included; it is Prof. Doolittle's intention to re-measure all the stars discovered by this observer.

The micrometer, the corrections of the instrument, and the method of observing are all fully discussed in the present publication, which is a continuation of part iii., vol. i.

Part ii., vol. ii., of the same publications gives the results of the observations made with the zenith telescope of the Flower Observatory from October I, I90r, to December 28, 1903, and also contains a re-discussion of the $1896-1898$ series, of which the details appeared in part ii., vol. i., in 1899 .

ObSERvations OF COMET I905c.-Numerous observations of comet $1905 \mathrm{c}$ are recorded in No. 4090 of the Astronomische Nachrichten.

This object was observed at Vienna from December 17 1905 , to January 14, 1906, and during that time its apparent diameter increased from $2^{\prime}$ to $4^{\prime}-5^{\prime}$, the length of its tail from $5^{\prime}$ to $40^{\prime}$, and its total magnitude from 9.5 to 4.0 . On December 30 a nucleus of magnitude 6.0 was observed.

Heliometer observations at the Cape Observatory showed the comet as a faint nebulous mass with no visible nucleus. Observations of position were recorded from February 5 to February 20, 1906.

The observations at Strassburg Observatory extended over the period December 1o to March 21, and the apparent position, the total magnitude, and the diameter were recorded on eleven different dates.

A Lunar Tide on LaKe Huron.-Whilst examining the curves showing the periodical oscillations of the seiches on Lake Huron, Prof. W. J. Loudon, of Toronto University, was struck by the regularity of their general out line, which seemed more marked in calm weather. Further investigation of the matter showed a well-marked and regular rise and fall twice a day, and also showed that no oscillation of the lake could have a period of more than four hours.

From these facts Prof. Loudon concluded that a true lunar tide occurs on Lake Huron, a conclusion which his further experiments seemed to verify.

\section{THE HAUNTS OF THE OKAPI.}

A CCORDING to a report in Monday's Times (May 2 1 ) charge of Captains Boyd Alexander and C. B. Gosling has been successful, not only in procuring a fine skin (and it may be hoped a skeleton) of the okapi, but likewise in obtaining some important particulars with regard to the habits of this animal. The specimen, which it is stated will ultimately find a home in the Natural History Branch of the British Museum, was obtained at Bima, on the River Welle, in the northern territory of the Congo State. It is mentioned in the letter that the animal was seen alive by the expedition, but further particulars on this point are desirable, as it is not stated whether anyone but the Portuguese collector by whom it was trapped had this good fortune. The animal was caught in a pit according to native fashion, previous attempts to shoot it having proved ineffectual.

Hitherto the only definite account of the kind of country inhabited by the okapi and the probable nature of its food is one given by Mr. J. David under the title of "Weitere Mitteilungen über das Okapi," and published in vol. 1xxxvi. of Globus (1904). Captain Alexander's notes, which differ No. I go8, voL. 747 in some respects from the former, are therefore of great value and interest, and may be quoted in full.

"The okapi here is generally found singly or in pairs, but Mobatti hunters state that sometimes three may be found together. An essential to the life of the okapi is a small stream of water with some muddy and swampy ground on either side. In this grows a certain large leaf that on its single stalk attains a height of 10 feet. It is the young leaf of this plant that is the favourite food of the okapi, and I venture to say that where the plant is not to be found the animal will not exist. During the night he will wander along in the mud and water in search of it. Here he may be found feeding as late as $8 \mathrm{a} . \mathrm{m}$. in the morning, after which he retires to the seclusion of the forest, where he remains until nearly dusk. On the three occasions that I was at close quarters with the beast, he was perfectly concealed in this swamp leaf. Near the River Welle I found his spoor on ground frequented by buffalo and waterbuck, but this is unusual, and his companions in the forest are the elephant, the greater bushbuck, the yellow-backed and small red duikers. The okapi is very quick of hearing, and in that respect is classed by the Mobatti with the bushbuck (local name 'bungana'). In the forest here I consider this latter beast to be more difficult to obtain than the former. On the hunting ground of the first village that I visited I estimated the number of okapi as five or six, at the second and third nil; and twenty miles south in the forest, on very likely ground where my guide said they were formerly numerous, there was one only, probably owing to rubber-collectors who had been there."

Several specimens had been speared, shot, or trapped by natives shortly before the date of Captain Alexander's visit, but time did not admit of further investigation. The sex of the new specimen is not stated, but it is to be hoped that it will prove to be a male, as Sir Harry Johnston's example, now exhibited in the Natural History Museum, is a female. A pair of okapis are exhibited in the Congo Free State Museum at Tervueren, near Brussels, which also possesses other skins; and there are likewise a few other examples in Europe, notably one in Italy and another in Mr. Rothschild's museum at Tring. It is a great pity that the Belgian Government does not take immediate steps to publish coloured figures of its specimens in order to aid in solving the question as to whether there is more than one species (or race) of okapi. Important information on this point will, however, doubtless be afforded by the Alexander-Gosling specimen, which, it mav be hoped, will also indicate (if a male) whether the tips of the horns always protrude through the skin, and thus foreshadow the antlers of deer.

\section{THE TARAWERA VOLCANIC RIFT, NEW ZEALAND.}

M R. JAMES MACKINTOSH BELL, director of the New Zealand Geological Survey, contributes a paper to the April number of the Geographical Journal describing the present topography of the great volcanic rift of Tarawera, in the north island of New Zealand, and the changes which have taken place in the configuration of the region since the great eruption of Mount Tarawera on June 10,1886 , which is memorable for the destruction of the famous pink and white terraces, and their submergence in Lake Rotomahana.

Mount Tarawera lies near the centre of the Taupo volcanic zone, and about 135 miles south-east of Auckland. This zone, which has a breadth of some twenty-five miles, extends from near the great volcanic cones of Ruapehu, Tongariro, and Ngaurahoe north-eastwards to White Island, on the Bay of Plenty, a distance of nearly i6o miles. A great rift, which was the scene of greatest intensity of the I886 eruption, stretches from near Lake Okaro along the Tarawera range to Mount Wahanga, in the most northeasterly part. This rift, really a line of craters, forms a huge fissure about nine miles in length, cutting the summit of the range, and appearing on its south-western slope. It is divided into several somewhat distinct craters by low partitions, and on the south-west side a long narrow rift extends to the base of the hill, so far as the edge of Lake 
Rotomahana. Lake Rotomahana is a sheet of dirty, muddy green water, some three and a half miles long by less than two miles in the opposite direction, and with a maximum depth of 427 feet. In continuation along the same line, beyond Lake Rotomahana, are the deep holes forming the Black, Fourth, Waimangu, Inferno, Echo Lake, and Southern craters. Hot water and steam issue in larger or smaller quantities from these craters, the water finding its way to Lake Rotomahana.

The most remarkable feature of the region during the last few years has been the great geyser of Waimangu. This geyser was discovered in January, 1900, and is believed to have become active only a short time before that date. While playing, outbursts occurred nearly every day, and sometimes more frequently. Mud, sand, and immense boulders were shot up in huge columns of dirty black water. At some hundreds of feet above the water the column broke, showering boulders, mud, and sand back into the pool, and even high up on the walls surrounding it.

In July, I904, the great geyser suddenly ceased, and remained dormant for seven weeks and five days; then it are being made as to the movement of underground water. A further paper on this subject has now been issued as the result of investigations made by Prof. Slichter, No. I40, on field measurements.

This paper presents an amplified exposition of the method of measuring underground water as described in his former paper of 1902. It contains descriptions of the apparatus used for the laboratory study of wells controlling horizontal and vertical movements, and the result of these studies confirms the conclusions described in the former paper as to the possibility of measuring the flow of subsurface water with trustworthy accuracy. Some improvements that have been made in the apparatus as the result of experience are described.

The author shows that the flow of water in a given direction through a column of sand is proportional to the difference in pressure at the ends of the column, and inversely proportional to the length of the column, and is also dependent upon a factor which he terms the transmission constant of the sand.

Experiment shows that the resistance to the flow of water through sand is very great, the water having to pass through pores, usually capillary in character, and the diameter of which varies from one-fourth to one-seventh of the diameter of the sand particles. When the sand is not of uniform size, and is mixed with grains slightly larger, the effect is to increase the capacity of the sand to transmit the water. Where particles seven to ten times the diameter of the original sand grains are added, each of these tends to block the course of the water. For example, a boulder placed in a mass of fine sand checks the passage of the water, and the rate of flow decreases in proportion to the number of such boulders until the amount of the large particles is equal to about 30 per cent. of the total mass. After this the flow increases until the mass of fine particles becomes negligible, and the capacity to transmit approaches that of the mass of large particles alone.

These facts are shown to have an important bearing upon the capacity of gravels to furnish water to wells, or to transmit it in the under-

FrG. r. - Highest known eruption of Wainangu. flow to rivers.

Tables are given showing the transmission constant for sands and gravels of different sizes and different degrees of porosity.

It is also shown that the rate of fiow is affected by temnerature, a change from freezing point to $75^{\circ}$ nearly doubling the power of the soil to transmit water. This paper contains a great deal of information as to the discharge from wells used for irrigation or other purposes.

Paper No. I44, by Mr. Daniel D. Jackson, deals with the normal distribution of chlorine in the natural waters of New York and New England. The author shows that, with the exception of local deposits, the normal chlorine in natural waters is derived from the salt of the ocean, blown over the land by storms, and that it diminishes in amount as the distance from the ocean increases. This decrease is so definite that equal amounts of chlorine are found along lines generally parallel to the sea coast, thus affording a basis for the establishment of isochlors. Charts and tables are given showing the proportion of chlorine at different distances from the coast. The samples were taken from ponds or open water basins as far removed from human
On a previous occasion, in NATURE of December $2 x$, 1905, we gave a short account of the investigations that

No. 1908 , vol. 74] 